\title{
In and Out European Union. Widening, Immigration, Brexit in the Opinion of Students
}

\author{
Cristina Montesi ${ }^{1}$, Mario G.R. Pagliacci ${ }^{2}$, Monika Slupinska ${ }^{3}$, \\ Gabriela Boldureanu ${ }^{4}$, Daniel Boldureanu ${ }^{4}$
}

\begin{abstract}
European Union is crossing a delicate phase of rethinking caused by many factors. In this problematic context a comparative and questionnaire survey "In and Out European Union" has been carried out on three groups of University's students, attending socio-economics courses, from three countries of European Union (Italy, Poland, Romania) testing their level of approval on EU activity, their proposals for bettering EU policy, their opinions on a possible EU enlargement to other European and non-European countries, on migration policies, on Brexit. The results of the research can be briefly summarized. The attitude of students towards EU activity is positive, despite some critical observations referred specially to issues concerning their future. Most students disagree with Brexit, the most students want EU to extend only to European countries. Most students want EU to be more restrictive towards migrants and refugees.
\end{abstract}

Keyword: Keywords: European Union, Brexit, Migration, Economic Development.

\section{Introduction: reducing distances between European Union and citizens}

The current socio-economic-environmental context is in continuous and swirling change (and not always in an evolutionary direction): the development of artificial intelligence, automation, technological progress requires the adaptation of knowledge and professional skills of people (and, a fortiori, of young people) to the "structural" change in progress which should not be passively suffered, but governed (European Political Strategy Centre, 2017); changes in labour market imply smoother transitions between education and vocational training, between higher education and lifelong learning of adults, between education and the world of work, between nonformal and informal learning; the aging of the population, together with unemployment (above all youth unemployment) and the fall in the fertility rate in many European countries, unbalances economic sustainability of national social and health protection systems which need to be reformed; the increasing flows of immigration and refugees to European Union require more capacity to welcome in social and educational systems and greater capacity for cultural integration with respect to risks of social fragmentation, populism, xenophobia, violent radicalization; the widespread dissemination of ICT imposes massive digital literacy processes; the methods of communication on social

\footnotetext{
${ }^{1}$ Department of Economics, University of Perugia, Italy

${ }^{2}$ Department of Economics, Seat of Terni, University of Perugia, Laboratorio Athena in Terni, Italy

${ }^{3}$ Faculty of Economics and Sociology, University of Lodz, Poland

${ }^{4}$ Faculty of Economics and Business Administration, "Alexandru Ioan Cuza" University of Iasi, Romania

${ }^{5}$ Department of Biomedical Science, Grigore T. Popa University of Medicine and Pharmacy of Iasi, Romania
} 
media expose people to new risks (liquefaction of social ties, exposure to "fake news", disinformation, privacy violation, cyber-bullying) which need critical thinking and discernment; unregulated globalization and the instability of financial capitalism increases inequality among people, monetary, material, educational poverty, social exclusion, environmental imbalances, all phenomena which demand a reform and a modernization of European Welfare State systems and the search for greater equity and environmental sustainability.

European Union is facing all these challenges, which have been exacerbated by the recent economic and financial crisis and even if there are signs of recovery, more contingent than permanent, its effects are still weak and not homogeneous among countries and among territories within countries. Unemployment rates are falling (reaching 7.5\% in September 2017, which is the lowest rate recorded since November 2008), but they differ substantially from one country to the other and 18.4 million people are still unemployed, including 3.7 million of young people. The aim of financial stability following the recent sovereign debt crisis, to be carried out through austerity, has eclipsed growth policies and cut social policies creating a gap between European institutions and the citizens, especially those more harmed by economic crisis. For the first time, from postwar period, weak hope for young generation's social mobility is on the horizon. The precious achievements of European Union (freedom, respect for human dignity, rights, democracy, peace, commercial and monetary union) seem to have clouded over in front of economic and social hardship of large sections of European population, although many of the objectives of Europe 2020 Strategy (European Commission, 2010a), which included social and economic targets, have already been achieved or are in progress in many Member States.

In these last years some African countries bordering the Mediterranean and some Middle Eastern countries have been politically destabilized and this fact has created the most serious humanitarian emergency since Second World War: the generation of an incessant and remarkable flow of refugees (1.2 million of individuals only in 2015), especially towards Italy, as the first stage of their journey to other European countries (other immigration flows are to be ascribed not to war or conflicts, but to population growth, poverty, climate change). The lack of choral management of refugees' problem is jeopardizing European cohesion and solidarity, already crumbled by United Kingdom's exit from European Union. Border management and free movement of persons are now questioned in European Union and some countries have come back to the restoration of temporary checks at the frontiers and to the construction of barriers (like the wall along the Serbian-Hungarian border) (Martin and Rkibi, 2017).

Terrorist attacks in European capitals have also undermined in many European citizens the sense of hospitality and tolerance towards foreigners, while they have increased the need for security, control and protection. Eurosceptic, nationalistic and populistic parties have grown up in many European Union countries, pushing for disaggregation, on the wave of fear of immigrants, of religious intolerance, of disappointment for social exclusion and increasing inequalities, of disaffection from traditional politics and from European Union. History teaches us that European Union has crossed in the past different episodes of serious difficulty like the crisis of the present moment but has always been able to evolve. 
Several countries, representing new world powers (economic, commercial, military), are emerging and the fear of their invasion on markets instils in some leading nations the desire for a return to protectionism, which European Union is strongly going to oppose (European Commission, 2017e). The protagonist of new economic giants could lead in future to the erosion of the economic importance of European Union (today it represents $22 \%$ of world GDP), even if EU remains at the forefront of innovation especially in the field of decarbonisation of the economy, reduction of pollution, fight against climate change, energy efficiency, renewable energies, smart cities. In this tightening of competition, European Union public investments in research and development are even more necessary together with an industrial policy able to maintain and develop (paying attention to small and medium-sized enterprises) a solid, competitive and diversified industrial base in Europe, while facilitating the transition of manufacturing sectors towards a more efficient use of energy and of resources and towards production with lower carbon dioxide emissions. The desirable increase of European Union investments in traditional and advanced infrastructures, in human capital, in research, in environmental protection and energy saving, in public housing and education, in health, mitigating the constraint of Fiscal Compact, would be useful not only to support the aggregate demand in the short term, but also to prevent poverty and to raise long-term growth.

National egoisms are putting Paris climate agreement into discussions, while European Union works always for an inclusive, sustainable, smart growth. European Union is also the world's largest donor for humanitarian aid.

Many local conflicts between countries, like the quarrels between Russia and Ukraine, the concentration of Russian troops at Eastern borders of European Union, the war in Middle Eastern and in other African countries, the world tensions on nuclear weapons, the attempts to privatization of some global common goods in many places of the planet which generate counteractions, the new forms of attacks (cyber attacks and terrorism attacks), can increase uncertainty and slow down market exchange in addition to the return to protectionist measures introduced by some countries. This turbulent context requires thinking by European Union of a modern common defense, although diplomatic route is preferable for the resolution of disputes. In politics of dialogue European Union has always played a strategic role (think of the agreement with Iran on its nuclear program).

In this very problematic framework (European Commission, 2016a) is placed the emblematic survey "In and Out European Union", which was carried out on three groups of students from three countries of European Union (Italy, Poland, Romania) which, beyond its statistical representativeness, is a reliable thermometer of their feelings on the functioning, need of revision and destiny of European Union, in addition to a review of their opinions on some specific questions like EU enlargement, immigration and Brexit. The judgment expressed by the students on the present activity of European Union which collected an appreciation just at the average level and the judgment expressed on the future of European Union (largely optimistic in Italy and in Romania, more skeptical in Poland) surprisingly collimate with the most recent Eurobarometer's poll (European Commission, 2017a). The Eurobarometer survey, published in August 2017, reveals that current confidence in the EU stands at only $42 \%$ of sample investigated (it was $36 \%$ in 
autumn 2016 and 32\% in autumn 2015). Only 40\% of Europeans have a positive image of the EU ( +5 percentage points compared to 2016). According to this same survey most Europeans $(56 \%)$ are anyway optimistic about the future of the EU (+6 percentage points compared to 2016) despite the outcome of Brexit referendum. Finally, 68\% of Europeans feels like an EU citizen. As for the economy, although there are differences among the member countries, less than half of Europeans (46\%) believe that the current situation of their national economy is "good" ( +5 percentage points compared to autumn 2016; + 20 points from spring 2013, +26 points from spring 2009). In spite of national economic difficulties, in Euro area around three quarters of the respondents expressed themselves in favor of euro (73\%), the highest score since autumn 2004 . The main challenges to face in the future according to people interviewed are: terrorism (44\%), immigration (38\%), economic situation (18\%), the state of public finances of the Member States (17\%), unemployment (15\%). For the first time Eurobarometer 2017 spring survey assessed the perceived image of European Union in eleven non-EU countries (Australia, Brazil, Canada, China, Japan, India, Norway, Russia, United States of America, Switzerland and Turkey) which represent $49 \%$ of world population and $61 \%$ of global GDP. Respondents in most of countries involved have a positive opinion of EU: $94 \%$ in Brazil, $84 \%$ in China, $83 \%$ in India, $76 \%$ in Japan, $79 \%$ in Canada, $75 \%$ in USA, $67 \%$ in Australia and 54\% in Turkey. At the same time respondents from countries closer to EU (Russia, Norway and Switzerland) who have a positive perception are less numerous (their percentage is between $43 \%$ and $46 \%$ ). The survey also shows that, in most of the countries extra-EU where the survey took place, EU is perceived as "a place of stability in a world in difficulty", but with important differences among countries: in Russia only 33\% share this opinion.

The reasons for the greater enthusiasm towards EU showed by non-European citizens in comparison with European citizens (also the students interviewed in our research were quite lukewarm in the judgment) may reside in different factors: the scarce knowledge by European citizens of the clear division of duties and responsibilities between EU and the Member States; the lack of institutional marketing by EU; the insufficient communication, made at local level, of the contribution of EU to economic and social daily life; the gap between people expectations and fulfillment which depends on the capacity of spending European funds by national and local authorities.

Analysing student's opinions on EU perspectives emerged from the investigation a clear image comes out: they would like a more united, active, cooperative EU, more committed to policies for economic growth and employment and for welfare than for macroeconomic stability. They share, very ideally, Scenario 5 of the recent European Union White Paper on the Future of Europe which debates on how Europe should evolve in the years to come. The White Paper offers a series of five scenarios which summarise the potential state of the Union by 2025 depending on the choices the Member States jointly will make. The alternative Scenarios proposed are the following: Scenario 1: Carrying on; Scenario 2: Nothing but the Single Market; Scenario 3: Those who want more do more; Scenario 4: Doing less more efficiently; Scenario 5: Doing much more together. Scenario 5 implies that: "Member States decide to share more power, resources and decision-making across the board. As a result, cooperation between all Member States goes further than ever before in all domains. Similarly, the euro area is strengthened with the clear understanding that 
whatever is beneficial for countries sharing the common currency is also beneficial for all. Decisions are agreed faster at European level and are rapidly enforced" (European Commission, 2017b, p.24).

In order to realize Scenario 5, in addition to the necessary policies (reinforcement of single market through harmonization of standards; completion of single market in energy, digital and services sectors; international trade of exclusive competence of European Union; implementation of economic, financial and budgetary union; systematic cooperation on border-management, asylum and counter-terrorism policies, creation of a common defense; transformation of the European Stability Mechanism into the European Monetary Fund), more pro-European conscience is needed, but the process of its formation is long and requires more culture and education. In education and in culture there is in fact the secret to build more environmentally responsible, inclusive and supportive societies and to strengthen European identity in the richness of all its diversity (European Commission, 2017c). Education is in fact the best antidote, both for children and adults, against unemployment, poverty and social exclusion. The future of children, economies and societies will depend on the development/updating of knowledge and skills of individuals (European Commission, 2010b; European Commission, 2017d, p.19). For this reason, higher public financial resources should be devolved to education than those currently invested by European Union countries, improving their effectiveness. Education is strategic not only for its economic and social implications, but also to promote, starting with the younger generations, the common European values of democracy, freedom, equality, tolerance and non-discrimination and active citizenship in more and more interconnected, liquid, mobile, multicultural, digital societies (European Commission, 2016b). Education and culture can in fact play a pivotal role for people to know better each other across borders and to experience and be aware of what it means to be "European" (European Commission, 2016b, p.3). But education is, more generally, also fundamental to face the three crises which afflict our planet: the economic-financial crisis, due to the structural instability of financial capitalism, which can for this reason be repeated over time, the environmental crisis and the crisis of meaning. Seven are the action concerning a new kind of knowledge that, according to Morin $(2012$, 2015) are necessary for the education of the Future (Auge, 2012): to be aware of the blindness of knowledge threatened by errors and illusions; to promote a "systemic" and "interdisciplinary" knowledge able to grasp the complexity of reality; to face the uncertainties; to teach human condition; to teach terrestrial identity; to teach mutual understanding; to affirm ethics of human race.

\section{The survey: Objectives, Hypothesis, Questionnaire}

European Union is in crisis of identity, which is involving and getting in doubt its existence and supranational sovereignty.

Additional widening processes are suspended owing to the guidance of present leaders in EU and several Member States.

In particular, two phenomena contributed in breaking up the image of EU:

- On the internal side the democratic decision, taken by Great Britain with an advisory referendum in June 2016, of leaving European Union; 
- On the external side the migratory pressure and consequent inflexibility by some Member States.

Possible overcoming of these criticalities - in addition to the solution of several ordinary and extraordinary problems - will be especially entrusted to the future ruling class, uncharged of important decisions and actions in national institution as well as in EU organization.

This survey - based of a short questionnaire (see Annex) - has the purpose to investigate on the opinions of university's students, attending socio-economics courses, concerning some critical European matters.

The survey is grounding on the principal hypothesis that most students are favourable to European Union, even if they can have a critical approach about some themes of their direct interest (youth unemployment, economic crisis, etc.). For verifying the hypothesis, we intend:

- Measuring the level of approval on EU activity expressed by students (see D.3 of the Questionnaire).

- Acquiring any knowledges and evaluations on possible axes for bettering EU policy (see D.5 of the Questionnaire).

Second hypothesis concerns attitude of students about the policy of EU towards the external. Taking in account that young are open to external world and to newness, we intend to verify if this usual youth approach is reflected on two fundamental themes: a) possible $E U$ widening to additional countries; b) opening of borders to migrants.

For verifying the hypothesis, we intend:

- Pointing out the strategic guidance concerning the widening policy of EU (see D.1 of the Questionnaire).

- Knowing opinions about two critical themes: Brexit (see D.2 of the Questionnaire) and migration (see D.4 of the Questionnaire).

For collecting a large panoramic of the students' opinions, we conducted the survey in three EU Member States, having different geopolitical characteristics. Three groups of University's students spontaneously redacted the Questionnaire during the months of February and March 2017:

- 105 in Italy: students of the Department of Economics, University of Perugia, Seat of Terni.

- 103 in Poland: students of the Faculty of Economics and Sociology of the University of Lodz.

- 77 in Romania: students of the Faculty of Economics, University of Iasi.

Additional information about the three groups of students are given in specific chapters. It is necessary to underline that the three groups were constituted on voluntary basis; as consequence, the results of the survey are not considered statistically representative of the universe. Nevertheless, the good numerosity of the groups authorizes to deem that the results of the survey give a good representation of the general thinking of the investigated students' people.

Finally, we note that the analysis of results for the three countries, are signed by different Authors, with a free style of writing, even if based on a common draft. As consequence, the analytic Part can be read like three separate papers. 
The comparative synthesis is proposed in final Part 4.

\section{The Survey on Italian Students}

\subsection{Statement of motives for the survey}

Crisis of European Union and causes of crisis instilled in citizens a sentiment of mistrust, which is progressively enlarging to young generation too. This fact is extremely grave, because young people - future ruling class - will be uncharged to operate for solving the causes of crisis and for maintaining and reinforcing European Union. Category of university's students is the nearest to be engaged in this task; the way and the attitude they will adopt for absolving their duty have strong influence on conditions of life and development of member States and the entire European Union.

These motivations inducted us to promote a survey for studying the opinions of University's students about some fundamental European matters.

\subsection{The Italian sample}

In Italy, the survey was addressed to university students attending at the Department of Economics, Seat of Terni, of "Università degli Studi di Perugia".

One hundred and five (105) students - females and males - were involved; they attended in academic year 2016-2017 the third year of $1^{\circ}$ level and the fourth and fifth years of specialist level.

The students participating to the survey represented a percentage of $66,65 \%$ of the total students in the academic year 2016-2017.

The participation of the students to the survey was completely free and voluntary; no casual criteria were adopted for building the group of students. As consequence, the resulting data cannot be assumed as statistically representative of the universe. Nevertheless, the number of returned answers authorize to consider the collected data adequately representative of the general thinking of students attending the course at the Department of Economics in Terni.

Concerning the period of administration of the survey, it started on February 20th and finished on March 10th, 2017.

\subsection{The judgement of student on the functioning of European Union}

The survey had a central matter concerning the grade of appreciation about the activity of EU. By demand D.3 students were asked to quantify their evaluation by assigning a score between 1 (minimum) and 5 (maximum). In addition, students were invited to write the motivation of their score. The 104 replies (only 1 did not reply) determined an average score of 2,596 - near to the centre of the variation field.

This result is not optimistic, especially if it is evaluated at the light of strong critical judgements expressed by some students. Certain assertions are striking; they consider EU "having no sense for existing", because "it is an institution anachronistic with scarcer dynamism" which is responsible to "have failed in achieving the fixed objectives". One student arrives to declare that EU had an "anti-war function and it is obsolete now". Actually, for 70 years from its starting, this institution assured peace among the members - so that EU received the 
Nobel for Peace in 2012 - but this fact does not means that the only role is "anti-war" nor this crucial function is now "obsolete".

The absolute negative ideas of some students are largely balanced by other opinions; they are critical, but do not refuse the role of EU. Nevertheless, they denounce "the worst treatment of some economic and social problems concerning several member states" owing to "low consideration of the effective problems of each country" and owing to the bureaucratic machinery that "does not take in account of the different national contexts". Other students point out "not efficient adjustment of rules in different countries" or "too many constraints in some domains and few constraints in other ones" or "too much penalties and too few incentives". Several students declare the opinion that the institutional entities of the Union are influenced by the stronger states ("excessive centralization of power of Germany"), so that are assumed decisions not favourable for the members in difficulties ("none member state belps Italy about reception of immigrants"). The consequence is in having an "ideal Union only, lacking for a homogeneous economic and financial system". In our opinion, one of the most level-headed opinion proposes "the activity of EU might be focused more on the themes of integration, sustainable economic development, cooperation among the states and be less focused on finance".

In general, $61 \%$ of opinions is oriented in critical or negative way, while only $14,3 \%$ concern favourable opinions. They put in evidence that EU is able to bring benefits to citizens, so that "we might feel European citizens more" in spite of limits and deficiencies; a "unitary and efficient system, but not perfect" having some lacks that can be corrected.

The open inquiry D.5 ("I WOULD LIKE THAT EU ..."), allows achieving an additional investigation on the student's thinking, they were completely free to express their opinion in any area of interest.

\section{WOULD LIKE THAT EU...}

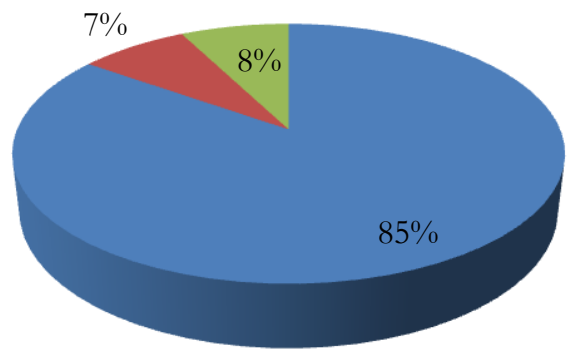

Improvement Proposals

Negative or destructive proposals

No Answers

Figure 1 The inquiry D.5 "I WOULD LIKE THAT EU ..."

At aggregate level, at first we note a modest percentage $(7,6 \%)$ of students demonstrating total negativity towards the Union ("stop to exist!!!"; "to get loose") or using strong critical words:" It is clear that in this situation it is not possible to continue with present politics, full of finance and balance sheet, but empty of ideas, visions and bumanity. It is perceived an abyss between the European institutions and European citizens". A student expresses the hope that the Union should became "a community rather than a hard and often surly union". Although present 
Union is defined hard and surly, this opinion opens to a positive approach, by hoping for a future effective community. A positive thinking concerns $84,8 \%$ of replies; in different ways they declare expectations and proposals about the future improvement of EU functioning.

Taking in account the variety of opinions, we grouped them in homogeneous thematic. The groups were suggested by a student who hopes the EU be engaged "with more seriousness on some important problems: defence of borders, distribution of migrants among member states, youth unemployment, sustainable economic growth, integration among different people".

Immigration: the opinions are divided in radical way between favourable and contrary. Some students have a good disposition towards immigrants, hoping that EU might "manage the question of immigrants on giving to each country the tools for receiving them, by assuring the freedom of moving and equal procedures, equal rights and duties existing in hosting countries". It is also asked "to offer to immigrant's better conditions, assuring that in hosting countries should be a work for them ". On the contrary, other students demand that EU "would be more rigid about immigration matter (it is a plague of any economic system) because rich economies (i.e. Italy) are falling in poverty now". EU is asked to "take more care to European citizens than to migrants/extracommunitarians". This subject is tightly linked to the thematic of security: "more security and control against an unrestrained immigration" are claimed and the adoption of "more efficient immigration politics concerning as widening as expatriation of dangerous persons".

Economic crisis: economic emergency was another sensitive theme, especially for students attending to economic courses. Perception of Italian critical situation influenced the demand that EU "should adopt an economic policy less rigid, favouring the growth of the countries which are now suffering of a grave internal economic crisis". The auspicious is that EU can "support the countries needing for specific economic and regulatory aid, so that the citizens can benefit of them. In other words, when EU adopts communitarian's rules, they might take in account of the situation of any country. Are necessary specific regulatory issue in favour of European individuals also". Another student underlines that EU must respect "the role of institution, which must be devoted to the welfare of most members, and not only to a restricted minority of members having deficit/GDP into the limit: in fact, this indicator simply represents a stability ratio".

Work and Youth employment. the status of university's students, not far for searching a work, gave the emphasis to this thematic. The auspicious is "the European Union could give better aid to young, students, unemployed people, useless engaged in finding a work; they must emigrate in more industrialized countries, as England or Germany". EU is strongly asked to respect "the assigned duties and to control on the activities of member states, especially concerning amendments about work". Particular citations concern "youth work orientation by adopting focused school programs" and "job accompaniment".

Functioning of $\boldsymbol{E U}$ : some students express their expectation in favour of stronger relationships among member states, in order to pursue a "federal status where countries are more linked, and the citizens feel to be part of this over-national organization, even if member states maintain a part of sovereignty". This solution could "transform Europe in a kind of unique state, similar to USA. This is difficult owing to internal insoluble differences among countries; but a more intensive engagement could assure better opportunities in economy, work and growth". Other opinions are "in favour of a solid organism, able to valorise principles of solidarity, collaboration, reciprocity ... but this is a utopic project". The objective must be that "EU takes in account of the internal difficulties of countries in settling rules and standards to be respected; they must play as a support for 
states development, rather than an obstacle". The EU must adopt "more just and flexible procedures on the theme of social policy, supporting the spirit of belonging which is lost now (Brexit is the demonstration). I would like a Union more secure, cooperative, without authoritarianism and imposition, without classification and distinction among $A$ and B countries".

In addition to above specific subjects, some students expressed opinions having strategic value on thematises of large interest, concerning their expectations about the functioning and development of Union. In addition, following citations were given in response of the D.5: I WOULD LIKE EU...

- "be more present in choices of single states and help members in difficulties. As a European citizen I believe in EU engaged in promoting the sharing of different culture and stimulating the appurtenance to the community by diffusing additional consciousness and teaching that appurtenance is an advantage?"; - "be less bureaucratic, more able and resolute in getting the important decisions; I would like a European Union more united, where each member is more disposable in charging a part of problems of others";

- "be an effective alternative to United States and other global Powers. I would like it be a fortress towards the external. I would like that each member state can obtain advantages and not constraints by the appurtenance to European Union. Notwithstanding I strongly believe in union of European states"; - "be accepted not Mediterranean countries also, in order to calm the situation, we are living now. Different culture and habit might be known more for avoiding prejudices against what it is not familiar"; - "become an effective union, without any kind of internal discrimination. EU should be able to demolish any type of barrier (geographical, technological, and so on) and in the same time be able in maintaining an adequate control - economic and in theme of security - towards each social class of the Union. No losers and no winners".

This panoramic of opinions cannot create any doubts about the expectations of students: they are addressed towards a qualitative and quantitative growth of European Union, in order to make EU stable and efficient in the internal, robust and authoritative on the external.

\subsection{Focus on some topical subjects}

Another part of the survey was addressed to specific thematises: EU widening policy, divorce of Great Britain (Brexit) from European Union and the thorny problem of immigration.

Question D.1 opens the questionnaire about the possible incremental widening of EU towards new countries. This matter is strategic for the future of EU but, at the same time, it is critical. In fact, the techno-political structure of EU - after the last entering of Croatia (2013) - publically expressed the wish to slow down the process of widening. President of European Commission Jean-Claude Juncker declared since his beginning that the widening process must be stopped for five years at least. Several European leaders confirmed this position on declaring that it was necessary a meditation about the effective possibility to accept new members.

Taking in account of this framework - but on the opposite the candidatures of several states for entering in EU - it was important to know the opinion of students. The result was that $46,7 \%$ of replies were in favour of the widening, but it must be open to continental (Europe) countries. Only 5,7\% were favourable in opening EU to Mediterranean countries (Pagliacci, 2017). The other half of replies are averse to any 
widening $(25,7 \%)$ or did not expressed any opinion $(21,9 \%)$. In synthesis, 52,4\% is favourable to additional widening, clearly oriented towards a strictly continental context, not out the European borders.

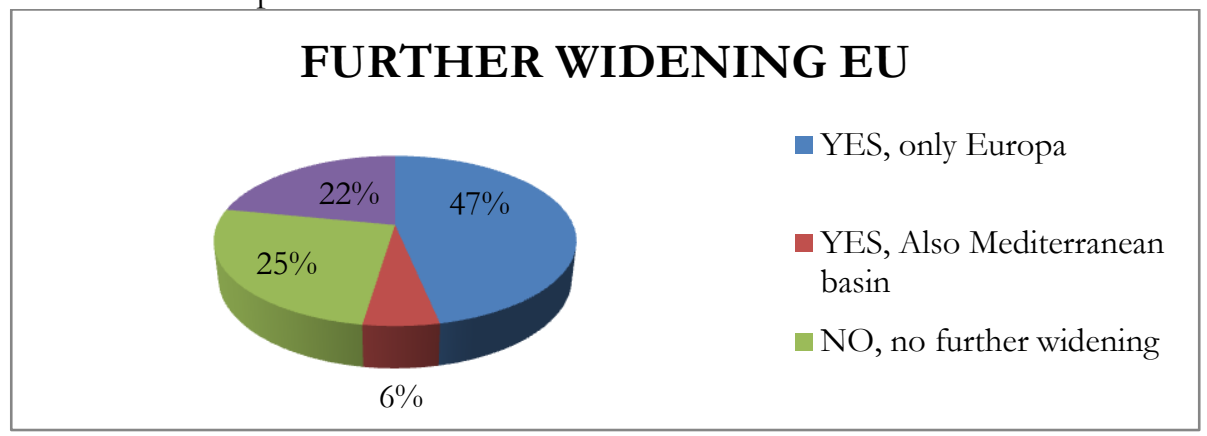

Figure 2 The inquiry "Further Widening EU"

Also, opinions about exit of Great Britain to the EU (conform D.2) present a clear separation: $40 \%$ of students agree with Great Britain decision, while 50,5\% do not agree. A part the specific meaning of this question, it is possible to look in this result a deeper explanation: students that agree with Brexit decision (40\%) represent the most critical group in opposition to EU, which is unable to satisfy the needs of members, so causing exit tendencies. Let us remind the declaration of a student, regretting about "lost appurtenance spirit" and declaring that "Brexit is the demonstration".

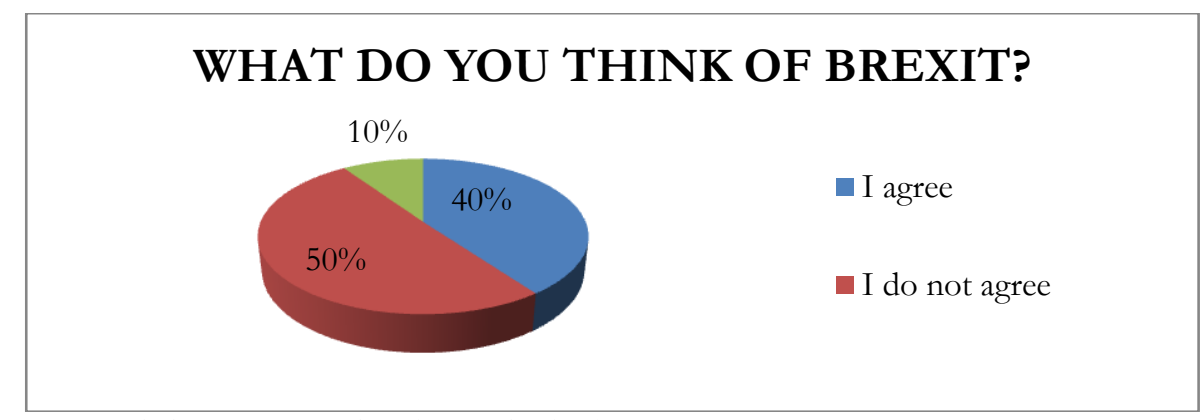

Figure 3 The inquiry "What do you think of Brexit?"

Finally, the question of reception of migrants (conform D.4). The orientation of students is clear: $71,4 \%$ is in favour of rigid policies to be adopted by EU, while only $21,9 \%$ in favourable to more flexibility. This result is in contradiction with the general perception that youth thinking and acting is particularly open to external world. Quantitative data (71,4\% is a high percentage!) as well as qualitative motivations expressed by students (see above) impose to deny this hypothesis. 


\section{HOW SHOULD BE EU IMMIGRATION POLICY?}

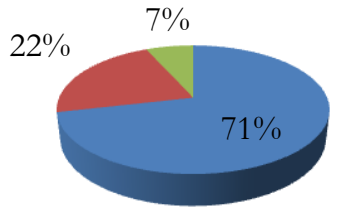

More strict

More open

- No Answers

Figure 4 The inquiry "How Should be EU Immigration Policy"

Students see a menace in migrants, at least under the point of view of potential competition in labour market and diminishing of public resources; also, internal security is their trouble, connected with criminality and terrorism phenomena. First motivation concerning competition on labour market - is weak, taking in account that activities generally accessible to immigrants are of low level of professionality or in micro-service areas: these applications are not appreciated or refused by Italians. Eventually is more solid the motivation concerning internal security, even if it concerns a marginal quote of migrants. In fact it is not possible to ignore the content of "Relazione sulla politica dell'informazione per la sicurezza 2015" (Report on information policy for security 2015). On the 2nd of March 2016, Italian Intelligence notified to the Parliament that "the flow of people moving towards community space, represents an emergency under humanitarian, sanitarian and public order point of views, but it can present perils in security field also".

In front the phenomena of immigration none can get estranged or to take refuge in culpable indifference, by waiting the problem is self-solved or is solved by others.

European Union must have and express the authoritativeness in adopting solid and coherent strategic and operative guidelines; in addition, it must demonstrate to have the authority for obtaining the respect of member states. These conditions did not happen until now, so that EU uncertainness's and weaknesses reversed in European citizens and especially in youth generation.

The results of our survey are clear demonstration.

\section{The Survey on Polish Students}

\subsection{Background of the research conducted}

In February and March 2017 was carried out a study among the students of the University of Lodz to learn about their views on issues such as their position towards further enlargement, views on the migration crisis or on the satisfaction of being a citizen of European Union.

Study leading to get to know the opinions and views of young people is more than an interesting research project. United Europe is currently experiencing a serious crisis. This is caused by many factors. The most important are the migration crisis and the difficult situation on the labour market (especially for young people). Unresolved issues have 
become a breeding ground for the strengthening of populist, nationalist, and often antiEuropeanist movements. In Poland, the disappointment of the mainstream party (Civic Platform) brought victory in the election of the Law and Justice party (declaring attachment to European values, but in reality, conflicting with those values, as evidenced by the critical opinions of the Venice Commission on the functioning of the legal system and the conduct which Poland launched the European Commission last year). For the first time an anti-system group, the Kukiz'15 party, was also elected to the parliament, mostly voted by young people disappointed by the current policy of the ruling party. This party, starting in the elections that took place in 2015, did not have a very clear and broad political agenda. Its main postulates come down to two terms: the introduction of single-member constituencies and the overthrow of the party's power system. The Kukiz'15 Party is still not a formally registered political party, it is called a movement. There are also representatives of national movements among the Kukiz'15 parliamentarians, expressing themselves strongly against the presence of Poland in the European Union.

The popularity of populist and anti-European movements is not only a phenomenon occurring in Poland, we also observe them in other European countries. The concern, however, is the increasing popularity of this type of movement among young people, who in the future will become significant group of voters throughout the whole European Union.

Considering these issues, it is worth looking at the attitudes of young people to the current problems of the European Union. Their opinions on issues related to the functioning of the EU are of great importance for the European project in the future.

The results of the survey conducted among students of the University of Lodz allow us to approximate the conclusions about attitudes of young Poles concerning the current problems faced by today's European Union. Of course, the results should be interpreted with extreme caution. The results cannot be extrapolated to the entire population of young Poles - primarily because the study was covered only by students, people being inside the academic system. Their views and opinions cannot be compared with the opinions of their peers without education.

\subsection{Methodology and research sample}

103 students of the Land Economy (taking part of undergraduate and postgraduate programmes) participated in the study. The study was conducted in February-March 2017 in the seat of the Faculty of Economics and Sociology of the University of Lodz. The study was based on standardized research questionnaire. The questionnaire contained closed and open responses.

\subsection{Analysis of the study results}

The first question points to a certain "closure" of Poles to the issue of further EU enlargement. On the question of further enlargement, the respondents responded positively - $68.9 \%$ (71 replies) said that the European Union should continue to expand, but only European countries should be accepted. 13.6\% of respondents (14 recommendations) believe that the Mediterranean countries should also be admitted to 
the EU. However, the "closure" confirms $17.5 \%$ of responses (18 indications), expressing the view that more countries should not be admitted to the European Union.

\section{The attitude of Polish students regarding the EU future enlargements}

68,9

17,5

YES, ONLY EUROPEANYES,UNLSBIESEDITERRANIAN CONOOURROHSE ENLARGEMENTS

Figure 5. The attitude of Polish students regarding the EU enlargement policy

In the second question, respondents were asked to answer the question about the British decision on exit from European Union. 21.4\% (22 replies) believes that this is a right decision and shows full understanding to it. 62.1\% (64 votes) thinks this is a bad decision. However, it is disturbing that 16.5\% (17 replies) claim that the Brexit decision "does not affect me".

This proves insufficient knowledge of geopolitical relations in Europe and the functioning of the European Union itself (including its budget). If such a high percentage of educated young people have such a mind, then the anxiety arouses as to other young Poles, especially the less educated. Another issue is the presence of many immigrants in Poland in the UK. Poles are the largest group of economic emigrants and the clear majority of them do not declare their willingness to return to Poland.

\section{Perception of Brexit by Polish students}

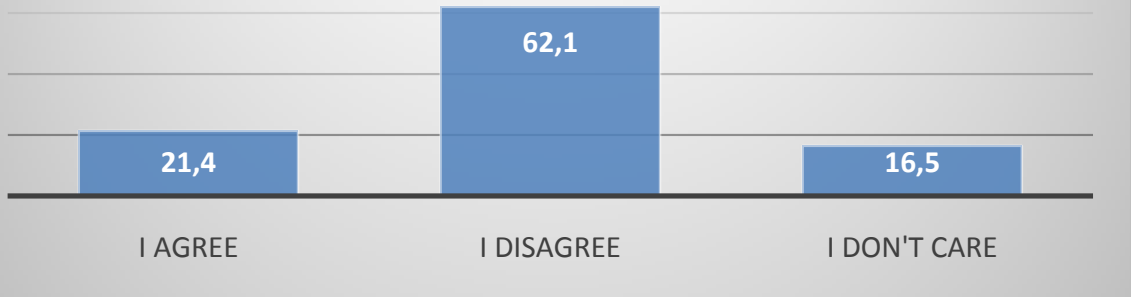

Figure 6. Perception of Brexit by Polish students

On the next question, respondents were asked to evaluate the European Union's activities in general. On a scale of 1 to 5 the students taking part in the study assessed 
this activity at 3.005. Unfortunately, none of the students decided to support the assessment expressed with any of arguments. Therefore, the answers to this question do not allow analysis and do not contribute much to the study.

Pessimistic conclusions are drawn when analysing the answers given to the question of the current migration crisis. It is important to note here the almost complete blockade of young Poles on issues related to the reception of immigrants. As many as $92.2 \%$ of respondents (95 replies) believe that the European Union should pursue a more restrictive policy towards accepting refugees. In principle, these are results similar to those expressed by Poles in other studies. Only $7.8 \%$ of respondents ( 8 replies) believe that the EU's policy on admitting immigrants should be milder.

\section{EU policy towards the admission of migrants should be...}

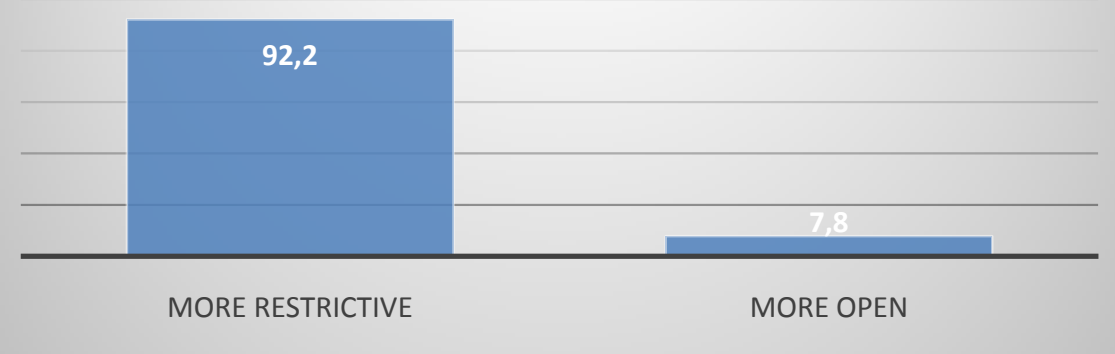

Figure 7. Opinions of Polish students on the migration crisis

At the last question the respondents were asked to complete the sentence: "I would like the European Union ...". The results given to this question are not optimistic. Only 4 out of 103 respondents "answered", 1 responded "disappeared", while 94.2\% (97 replies) did not comment. Unfortunately, this leads to little interest in public affairs, even so important for young people as their country's membership in the EU and the future of this grouping.

\section{The Survey on Romanian Students}

The aim of the research is to identify students' attitudes towards a series of critical issues concerning the European Union: the EU activity and enlargement, the Brexit and the immigration phenomenon and is based on the following objectives: a) knowledge of the degree of satisfaction expressed by students about EU activity; b) identifying and evaluating possible lines for improving EU activity; c) determining the strategic orientations regarding EU enlargement policies; d) knowing the students' opinion upon two critical issues: the Brexit and the immigration. 


\subsection{Methodology and research sample}

To identify Romanian students' attitudes towards many critical issues regarding the European Union, a questionnaire survey was carried out on a number of $77 \mathrm{MA}$ students from the Faculty of Economics, University of Iasi. The administration period of the questionnaire was February 20 - March 10, 2017. The statistical analysis of the data was carried out using the SPSS system, 18.

\subsection{Analysis of the study results}

a) The attitude of Romanian students towards EU policy and activity is positive, with the average of answers of 3.03 (the highest of all analyzed countries)

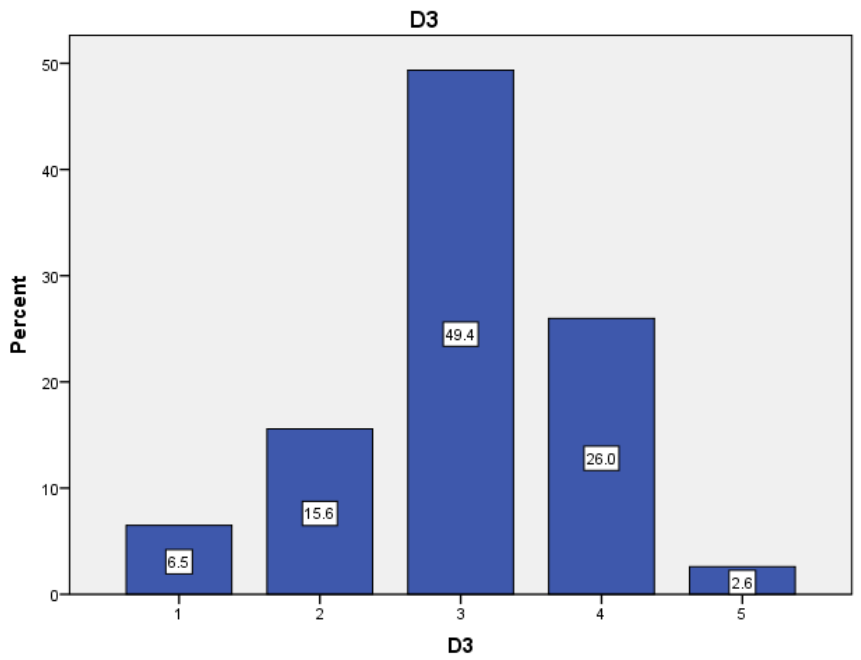

Figure 8. The attitude of Romanian students towards the EU policy and activity

We notice that the response distribution is a normal Gauss-Laplace type, most respondents $(49.4 \%$ ) on a scale of 1 (minimum) to 5 (maximum) awarded the score 3, which means a medium-level activity attributed to the European Union (Figure 8).

Among the positive motivations posed by students about EU activity and policy, we mention: the EU provides opportunities for education (Boldureanu, 2013), research, tourism, jobs and free movement for the EU citizens; the EU funded projects are real aid to our country and other member countries; the EU maintains the interstate contacts; in the opinion of some students, Romania has seen a faster development since joining the EU; the business environment, through the creation of international contacts, has experienced a steady growth.

In addition to these positive aspects appreciated by the Romanian students, some of them $(22.1 \%)$ considered the EU policy and policy to be poor and among the arguments we mention: it is necessary to solve some internal and external policy issues; the slow 
steps in resolving the issue of immigrants and in preventing terrorist attacks; the discriminatory treatment in the approval of projects with European funding.

\section{b) Identification and assessment of possible lines for improving the EU activity}

The EU policy and activity are amongst the concerns and interest of the Romanian students because most of the students surveyed said that Romania has experienced progress, a development on all fronts because of having joined the EU. However, the EU activity requires a number of improvements, and the interviewed students suggested the following: the careful management of the immigrants' issue; promoting a nondiscriminatory treatment among the member countries; the EU should be more involved in the eradication of poverty, illiteracy, school drop-outs and family abandonment; the creation of more study offers and facilities in the EU; more job offers for graduates; the support of young people from less developed (ex-communist) countries through career opportunities without having to emigrate.

We note that the main lines of action proposed by the Romanian students, aiming at strengthening the place and the role of the EU, are as follows: increasing study and job offers, eradicating poverty, illiteracy, domestic violence and, finally, terrorism.

\section{c) Determining the strategic orientations for the EU enlargement policies}

About the EU enlargement policy, most surveyed respondents $(62.3 \%)$ want EU to extend only to the European countries, while $19.5 \%$ of the interviewed students want the EU enlargement to include non-European countries. A $10.4 \%$ of those interviewed do not want U.E. to extend (Fig.9).

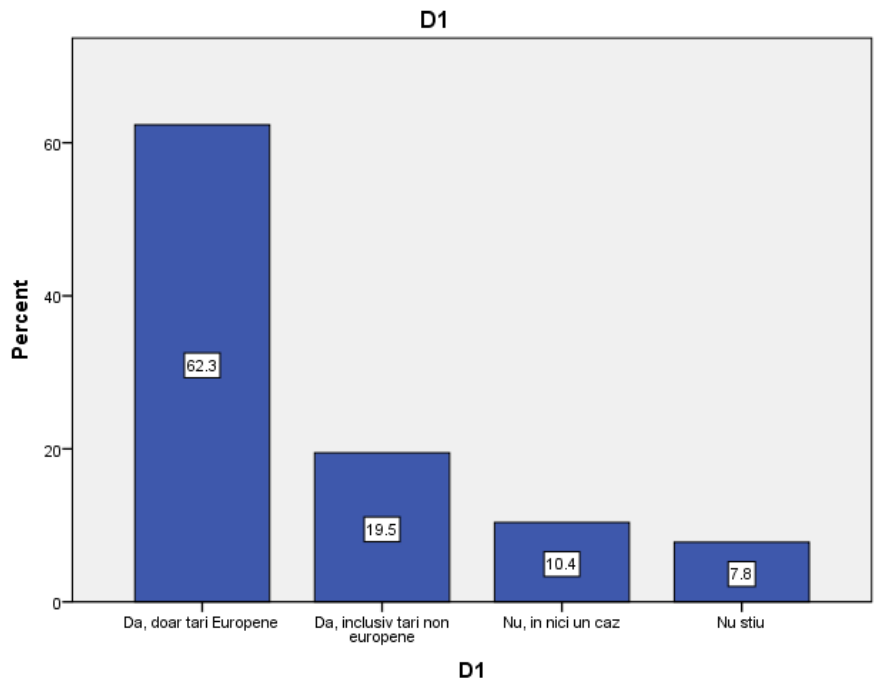

Figure 9. The attitude of Romanian students regards to the EU enlargement policy

d) Knowledge of the students' concerning two critical issues: the Brexit and the immigration issue 
The recent exit of Britain from the European Union has created a wave of rather negative reactions at the level of the European community. In Romania this strategy of Great Britain contributed to the increase of uncertainty and mistrust especially for the Romanian immigrants settled in this country. Moreover, according to Romania's Statistical Yearbook 2016, in 2015 alone, most Romanians chose to emigrate to the UK (53.000), followed by Romanians who emigrated to Italy (39.000) and then to Spain (27.736). The interest in obtaining residence in the UK is more significant as there is a considerable increase in the number of Romanians who want to work, study and settle in that country. If in 2013 the number of Romanians who chose to leave for England was 17.250, in 2014 the figures almost doubled (34.000), reaching 53,000 in 2015.

That is why Brexit is a big question mark for Romania, raising concern for the present and future situation both for the Romanians settled in England and for those who want to emigrate to this country in the future.

The survey of the students reveals this concern, which is why most of the respondents (48.1\%) disagree with the BREXIT; those who agree with BREXIT are $26.0 \%$, the same percentage as those who state that this problem does not address them (Figure 10).

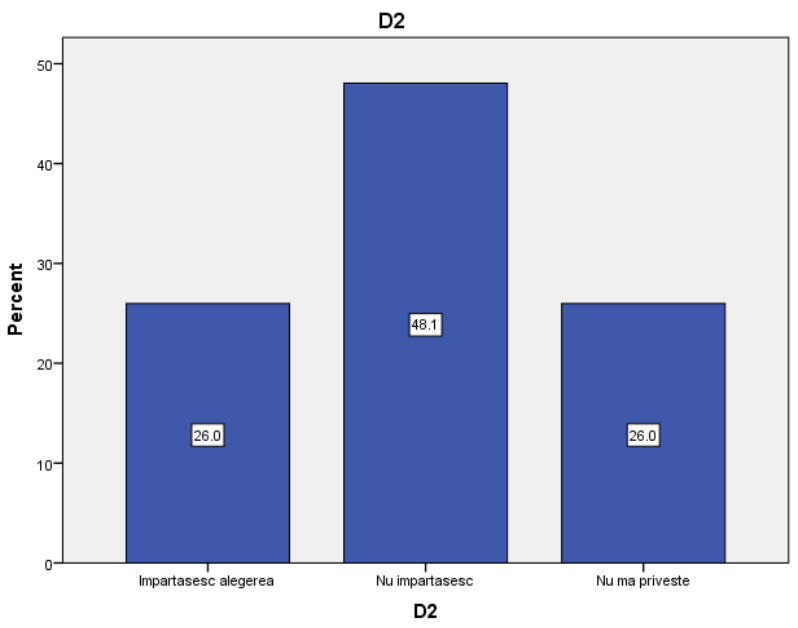

Figure 10. The attitude of Romanian students regards the BREXIT

The issue of immigration in the European Union has become extremely serious, especially because of the terrorist attacks that have taken on an unprecedented scale. Therefore, the opinion of most Romanian respondents $(80.5 \%)$ is that the U.E. should be more restrictive with regard to the issue of migration, and only $19.5 \%$ of the respondents said the EU should be flexible and welcoming in relations to the immigrants. The situation is shown in Figure 11. 


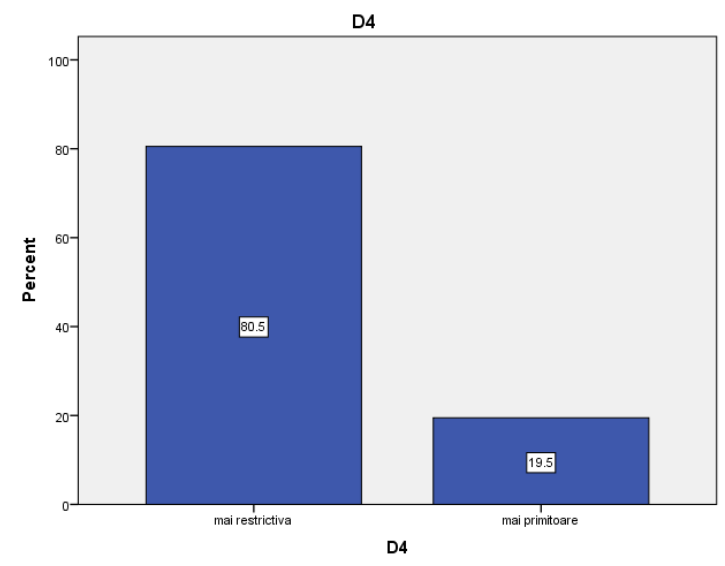

Figure 11. The attitude of Romanian students towards the immigration

As a result of the analysis, the first hypothesis is verified, which shows a positive attitude of the Romanian students towards the EU, while the second one is not verified because $62.3 \%$ of the interviewed students want U.E. to extend only to European countries, and $80.5 \%$ of them want restricting access to the EU, mainly because of the recent terrorist attacks.

In conclusion, the Romanian students have a positive attitude towards the EU's policy and activity. According to their opinion, Romania has experienced an evolution, a development on all the plans because of having joined the EU. However, the activity of the EU requires many improvements and the students have mainly suggested the increase in study offerings and jobs, the eradication of poverty, illiteracy, domestic violence and, last but not least, terrorism.

Regarding the strategic guidelines for the EU enlargement policies, most respondents surveyed $(62.3 \%)$ want the EU to extend to European countries alone.

The Brexit issue raises concerns about the present and future situation both for the Romanians already settled in England and for those who want to emigrate to this country, which is why the clear majority of the respondents $(48.1 \%)$ disagree with the BREXIT and with regard to the immigration phenomenon, most Romanians $(80.5 \%)$ want a restriction of the access to the EU, mainly because of the recent terrorist attacks.

\section{Comparison of Data}

Data concerning the three students' groups in their countries (Italy, Poland and Romania) evidence a similar position in the majority of the themes. Principal exception concerns the results of D.1 (see Table 1) about the eventuality of an additional widening of EU.

In fact, in comparison to Polish and Romanian students, Italian students demonstrate minor opening as towards other European countries, as towards countries of Mediterranean basin. In particular, must be noted the Italian low disposition towards Mediterranean countries, despite Italy is the only country - among the investigated ones - having a direct geographic flowing into Mediterranean Sea. As consequence it is 
possible to declare that the first part of our second hypothesis is partially confirmed:

Taking in account that young are open to external world and to newness, we intend to verify if this usual youth approach is reflected on ... possible EU widening to additional countries.

Table 1. Further widening of EU towards new countries (D.1)

\begin{tabular}{|l|l|l|l|l|l|l|l|l|}
\hline Description & Italy & \% Italy & Poland & \% Poland & Romania & \% Romania & Total No. & \% \\
\hline YES, only Europa & 49 & 46.7 & 71 & 68.9 & 48 & 62.3 & 168 & 58.9 \\
\hline YES, also Med. & 6 & 5,7 & 14 & 13.6 & 15 & 19.5 & 35 & 12.3 \\
\hline NO, no further widening & 27 & 25.7 & 18 & 17.5 & 8 & 10.4 & 53 & 18.6 \\
\hline I do not know & 23 & 21.9 & 0 & 0,0 & 6 & 7.8 & 29 & 10.2 \\
\hline TOTAL & 105 & 100 & 103 & 100 & 77 & 100 & 285 & 100 \\
\hline
\end{tabular}

About the opinion on Brexit (see Table 2), it is evident that the three groups of students "do not agree" with the exit of Great Britain: Italians and Romanians in minor quantity in comparison to Polishes. In the same time, it is important to note that $40 \%$ of Italians agree with Brexit: this high percentage could be interpreted as a signal of not satisfaction of Italians towards EU appurtenance, rather than a specific interest in Britain affairs.

Table 2. Brexit

\begin{tabular}{|l|l|l|l|l|l|l|l|l|}
\hline Description & Italy & \% Italy & Poland & \% Poland & Romania & \% Romania & Total No. & \% \\
\hline I agree & 42 & 40,0 & 22 & 21,4 & 20 & 26,0 & 84 & 29,5 \\
\hline I do not agree & 53 & 50,5 & 64 & 62,1 & 37 & 48,0 & 154 & 54,0 \\
\hline This does not concern me & 10 & 9,5 & 17 & 16,5 & 20 & 26,0 & 47 & 16,5 \\
\hline TOTAL & 105 & 100 & 103 & 100 & 77 & 100 & 285 & 100 \\
\hline
\end{tabular}

The signals of not satisfaction towards EU have a partial confirmation by the score assigned by students on EU performance (see Table 3). The average score of the three groups is similar and it is attested on a middle position only. In addition, Table 3 bis evidence that $61 \%$ of Italians express negative opinions about EU activity; Romanians have a modest favourable position (35,1\%); Polishes did not express any opinion, and this omission appears as a silent disagreement.

Table 3. Voting EU activity (D.3.)

\begin{tabular}{|l|l|l|l|l|}
\hline Description & IItaly & Poland & Romania & Total \\
\hline I agree & 2,596 & 3,005 & 3,030 & 2,862 \\
\hline No Answers & 1 & 0 & 0 & 1 \\
\hline
\end{tabular}

Table 3 bis. Mark motivations (D3 bis)

\begin{tabular}{|l|l|l|l|l|l|l|l|l|}
\hline Description & IItaly & \% Italy & Poland & \% Poland & Romania & \% Romania & $\begin{array}{l}\text { Total } \\
\text { N. }\end{array}$ & \% \\
\hline Positive Motivations & 15 & 14,3 & N.R. & 0,0 & 27 & 35,1 & 75 & 41,2 \\
\hline
\end{tabular}




\begin{tabular}{|l|l|l|l|l|l|l|l|l|} 
Negative Motivations & 64 & 61,0 & N.R. & 0,0 & 22 & 28,6 & 81 & 44,5 \\
\hline No Motivations & 25 & 23,8 & & & 28 & 36,3 & 25 & 13,8 \\
\hline No Answers & 1 & 0,9 & & & 0 & 0 & 1 & 0,5 \\
\hline TOTAL & 105 & 100 & 103 & 100 & 77 & 100 & 285 & 100 \\
\hline
\end{tabular}

On the theme of migration, data of the three groups evidence a high tendential uniformity (see Table 4). Even if percentages are variable (71,4\% Italy; 80,5\% Romania; $92,2 \%$ Poland) all are in favour of "stricter" regulation about migration. This result could be in contradiction with data of D.1 where partial disposition of Poland and Romania in favour of EU widening was registered. The apparent contradiction could be explained in the sense that the resistance of students against migrants is particularly addressed towards people and countries destined to be - and remain - out the EU area of direct influence: it is not difficult to think to Sub-Saharan Africa and Far East. Anyway, we must conclude that the second part of our second hypothesis cannot be confirmed; in fact, data concerning all three groups clearly demonstrate that the usual youth approach is NOT TOWARDS ... opening of borders to migrants.

Table 4. Immigration in EU (D.4)

\begin{tabular}{|l|l|l|l|l|l|l|l|l|}
\hline Description & Italy & \% Italy & Poland & \% Poland & Romania & \% Romania & Total N & \% \\
\hline More strict & 75 & 71,4 & 95 & 92,2 & 62 & 80,5 & 232 & 81,4 \\
\hline More open & 23 & 21,9 & 8 & 7,8 & 15 & 19,5 & 46 & 16,1 \\
\hline No Answers & 7 & 6,7 & 0 & 0,0 & 0 & 0,0 & 7 & 2,5 \\
\hline TOTAL & 105 & 100 & 103 & 100 & 77 & 100 & 285 & 100 \\
\hline
\end{tabular}

For concluding the survey, are noted - in qualitative way - students' auspices and suggestions for future of Europe. Quantitative synthesis is shown in Table 5. Italian and Romanian students expressed high level of positive proposals (over 80\%), attesting a kind of confidence towards EU. This is a verification of our principal hypothesis attesting that most students are favourable to European Union, even if they can have a critical approach about some themes of their direct interest. Not the same for Polish students, because $94,2 \%$ of them refused to give any answer, so giving a clear signal of indifference or extraneity.

Table 5. I would like that EU ... (D.5)

\begin{tabular}{|l|l|l|l|l|l|l|l|l|}
\hline Description & Italy & $\begin{array}{l}\text { \% } \\
\text { Italy }\end{array}$ & PPoland & $\begin{array}{l}\text { \% } \\
\text { Poland }\end{array}$ & $\begin{array}{l}\text { Romani } \\
\text { a }\end{array}$ & \% Romania & $\begin{array}{l}\text { Total } \\
\text { N. }\end{array}$ & \% \\
\hline $\begin{array}{l}\text { Improvement } \\
\text { Proposals }\end{array}$ & 89 & 84,8 & 5 & 4,8 & 62 & 80,5 & 156 & 54,7 \\
\hline Negative Proposal & 8 & 7,6 & 1 & 1,0 & 3 & 3,9 & 12 & 4,2 \\
\hline No Answers & 8 & 7,6 & 97 & 94,2 & 12 & 15,6 & 117 & 41,1 \\
\hline TOTAL & 105 & 100 & 103 & 100 & 77 & 100 & 285 & 100 \\
\hline
\end{tabular}


The comparison of data evidence a pose of perplexity that is present in all three groups. In our opinion, this perplexity is caused - partially - by scarcer or superficial knowledge that students have about Europeanist problematics; at the same time by evident deficiencies and frequent incoherencies present among member States, inevitably reversing on lacking and disputable decisions and actions of European Union.

On other hand, conflicts of interest among member States have not be ignored or minimized; they are the demonstration that the process of generation of Europeanist conscience and action is still at beginning; it is necessary a compact and tenacious activity of education, communication and sharing engaged by European Institutions. Until now, various and costly channels destined to communication and creation of consensus have failed in the purpose of supporting the Europeanist effort. New idea, new stimulus is necessary for making the European Common Home.

\section{Acknowledgement}

This work was supported by a grant of the Romanian National Authority for Scientific Research and Innovation, CCCDI - UEFISCDI, project number PN-III-P33.1-PM-RO-BE-2016-0012.

Cristina Montesi wrote Paragraph 1 of Introduction; Mario G.R. Pagliacci wrote paragraph 2; Part 3 (subparagraph 3.1, 3.2, 3.3, 3.4) and Part 6; Monika Slupinska wrote Part 4 (subparagraph 4.1, 4.2, 4.3); Gabriela and Daniel Boldureanu wrote Part 5 (subparagraph 5.1, 5.2).

\section{References}

Augé M. (2012), Futuro, Bollati Boringhieri, Torino.

Boldureanu, G., Lache, C., Păduraru, T., Boldureanu, D., Niculescu. N.,(2013) Students' entrepreneurial competencies and orientation. Current status and perspectives, Environmental Engineering and Management Journal, Vol. 12 (11), 2071-2077

European Commission (2010a), Comunicazione della Commissione Europea. Europa 2020. Una strategia per una crescita intelligente, sostenibile e inclusiva, 1-39.

European Commission (2010b), An Agenda for new skills and jobs: A European contribution towards full employment, COM (2010) 682 final,1-22.

European Commission (2016a), State of the Union Address 2016: Towards a better Europe-a Europe that protects, empowers and defends, Speech of President Juncker,1-9.

European Commission (2016b), Promoting citizenship and the common values of freedom, tolerance and non-discrimination trough education. Overview of education policy development in Europe following the Paris Declaration of 17 March 2015, Education, Audiovisual and Culture Executive agency, Brussels, 1-18. European Commission (2017a), Standard Eurobarometer 87, Public Opinion in European Union, Spring European Commission (2017b), White Paper on the Future of Europe. Reflections and scenarios for EU27 by 2025, COM (2017) 2025 final, 1-18.

European Commission (2017c), Strengthening European Identity through Education and Culture, The European Commission's contribution to the Leaders' meeting in Gothenburg, 17 November 2017.

European Commission (2017d), Reflection paper on the social dimension of Europe, COM (2017) 206 final, 1-36.

European Commission (2017e), Reflection paper on harnessing globalization, COM (2017) 240 final, 1-30.

European Political Strategy Centre (2017), 10 Trends transforming education as we know,1-12.

Martin C., Rkibi T. (2017) (ed.), La remise en cause del frontières: une nouvelle représentation de la réalité européenne, $\mathrm{UIC} / \mathrm{PGV}$. 
Morin E. (2012), I sette saperi necessari all'educazione del futuro, Raffaello Cortina Editore, Milano.

Morin E. (2015), Insegnare a vivere. Manifesto per cambiare l'educażione, Raffaello Cortina Editore, Milano.

Pagliacci M.G.R. (2017), Une Union inclusive, fondée sur la démocratie et le bien-être, in La remise en cause des frontières: une nouvelle représentation de la réalité européenne, UIC/PGV, 51-58.

\section{ANNEX}

\section{QUESTIONNAIRE}

Survey on university's students: opinion on European Union

Dear Student, thank you for participating to this survey.

Collected replies will be utilised in aggregate model. Nevertheless, single replies could be cited in case of particular content.

D.1 European Union is composed by 28 countries now. Do you consider available an increasing widening to other countries?

-- YES, European Countries only

-- YES, also not European countries, if located in Mediterranean basin (North Africa, Medium Orient)

-- NO, in any case

-- I DO NOT KNOW

D.2 Great Britain chose to leave European Union. What do you think?

-- I AGREE

-- I DO NOT AGREE

-- IT DOES NOT CONCERN ME

D.3 You are asked to assign a synthetic evaluation to the activity of European Union. What is your score? (1=minimum; $5=$ maximum)

Score

Your synthetic motivation

D.4 Concerning immigration, do you think that European Union must be:

-- MORE RIGID towards immigrants

-- MORE WELCOMING AND FLEXIBLE in procedures

D.5 Please complete following sentence with a synthetic opinion:

I would like the European Union ...

\section{UNIVERSITY}

Country

DEPARTMENT/FACULTY

Town. 
